\title{
En un futuro muy cercano las Humanidades serán Humanidades Digitales o no serán nada. Entrevista a José Manuel Lucía Megías
}

In the very near future the Humanities will be Digital Humanities or they will be nothing

Gimena del Rio Riande

Instituto de Investigaciones Bibliográficas y Critica Textual (SECRIT-IIBICRIT), CONICET, Argentina

José Manuel Lucía Megías encarna, sin duda alguna, el perfil de un humanista renacentista en pleno siglo XXI. Destacado académico e intelectual, este catedrático de Filología Románica de la Universidad Complutense de Madrid es, además de cervantista, experto en libros de caballerías, y destacado filólogo, editor, ensayista, poeta y curador de arte, uno de los precursores de la Informática Humanística y de las Humanidades Digitales en España y Latinoamérica. En esta área del conocimiento, José Manuel Lucía Megías ha trabajado, como buen humanista, en una reflexión sopesada sobre las capacidades del medio digital como vehículo de transmisión del saber en la Academia, sin olvidar la dimensión del hacer, diseñando y anticipándose a los años por venir, plataformas y métodos digitales para el trabajo filológico.

En el año 1998 publicó en la revista Incipit el señero "Editar en Internet (che quanto piace il mondo è breve sogno)", uno de los primeros artículos en lengua española que estudiaba con minucia los modos en los que internet podía transformarse en la gran plataforma de edición para la Filología. A este texto profético, que no deja de resignificarse año a año, le siguió una centena de publicaciones científicas sobre el tema, coronadas por el Elogio del texto digital, libro que ha adquirido un carácter central en los estudios sobre cultura digital.

Esta entrevista busca iluminar las motivaciones y los caminos que llevaron a este humanista de origen ibicenco a constituirse en uno de los grandes referentes en la materia. Es asimismo un pequeño homenaje al maestro de parte de una de sus discípulas, quien gracias a sus clases y a su guía se interesó no solo por los códices y su materialidad, sino también por las formas de construcción y circulación del conocimiento científico a través del tiempo y de los medios. Y es que José Manuel Lucía Megías, a la vez que enseñaba Filología, nos llevaba a visitar imprentas antiguas y nos mostraba herramientas digitales, y así siempre encendía la llama de la curiosidad sobre el cómo y el por qué entre sus alumnos.

Gimena del Rio Riande: ¿Cuál es su recuerdo más temprano sobre una computadora?

José Manuel Lucía Megías: Me estás pidiendo un verdadero viaje en el tiempo. A los 16 años, allí por el año 1983 o 1984, y no me preguntes la razón, comencé a acudir a una academia en Madrid para aprender a programar en Cobol y Basic. Allí vi y usé las primeras computadoras. Y por aquel entonces, con un gran esfuerzo económico de mis padres, tuve mi primer computador personal, mi primer Amstrad, con 4.7 Mhz y $256 \mathrm{~KB}$ de memoria. ¿Qué recuerdos! Tener que introducir primero el disquete $51 / 4$ con el sistema operativo, y luego sacarlo, para introducir el otro disquete en el que poder grabar la información. ¡Cuánto ha llovido y cuánto ha cambiado toda la tecnología digital desde entonces! Lamento ahora no haber sido más consciente de los cambios por venir y no haber guardado todas estas computadoras iniciales con lo que podría ahora montar mi propio museo personal. Conservo, eso sí, varios disquetes $51 / 4$, y desconozco la información que guardan. ¡Un misterio informático y filológico!

G.R.R: Y ya más tarde, ¿cuándo y qué o quién hizo que se interesara por el cruce entre las computadoras y la Filología?

J.M.L.M: Lo cierto es que nuestra generación, los que nacimos en los años sesenta y setenta, fuimos educados en un entorno analógico, y fuimos conociendo los avances informáticos a medida que se iban popularizando y llegando a las universidades. Es posible hablar de una doble vía de entrada en el fascinante mundo de la Filología Digital: por un lado, los ordenadores - cada vez con más capacidad de memoria y con 
una interfaz gráfica de usuario más intuitiva, después del éxito del modelo Mac y su adaptación a los PC por medio de Windows-, nos servían como sofisticadas máquinas de escribir (muchos profesores se han quedado en esta primera fase, me temo); y por otro lado, nos fascinaba la web -mucho más que internet- como medio de accesibilidad del saber, de poder digitalizar los fondos de las bibliotecas o de presentar nuestros textos o investigaciones en formatos más accesibles a la comunidad científica. En mi caso, el cruce entre las computadoras y la filología fue una casualidad: por el año 1996 trabajaba en la Dirección Académica del Instituto Cervantes y por ese entonces se comenzaron a sentar las bases de una biblioteca digital. Se me encomendó hacer un informe sobre las bibliotecas digitales ya existentes, y, tras meses de análisis, no solo aprendí mucho de lo que existía en la red, sino que me permitió comprender que el universo digital abría nuevas posibilidades al filólogo hasta ese momento imposibles de soñar. La biblioteca digital del Instituto Cervantes nunca se llegó a concretar, pero mi investigación fue publicada por Germán Orduna en 1998 en la revista Incipit: "Editar en Internet (che quanto piace il mondo è breve sogno)", que, para muchos, es una de las piezas sobre las que se ha levantado el complejo edificio de las Humanidades Digitales hispánicas. Desde 1997 no he dejado de reflexionar sobre el tema y de interesarme por las enormes posibilidades de desarrollo de la Filología Digital.

G.R.R:¿Cuál fue su primer trabajo sobre el tema y qué quiso expresar en él? ¿Le resultó difícil que se lo publicaran?

J.M.L.M: Como he dicho, mi primer trabajo sobre el tema fue "Editar en Internet..." de 1998. No me fue difícil publicarlo. Todo lo contrario: le envié un borrador del mismo al profesor Germán Orduna, al que siempre he considerado mi maestro en crítica textual, aunque nunca tuve el placer de asistir a sus clases. Mi intención era conocer su opinión, si iba muy descaminado en mi análisis y en esta primera clasificación que me había atrevido a realizar sobre los modelos de bibliotecas digitales que existían en la red por aquel entonces, dominadas por las propuestas anglosajonas e italianas. Mi sorpresa fue su carta manuscrita, que me llegó meses después desde Argentina: no solo me hacía varios comentarios elogiosos acerca de mi trabajo, sino que incluso me proponía publicarlo como primer artículo en el número de la prestigiosa revista Incipit, que saldría en ese año, 1998. Y recuerdo muy bien sus palabras, las palabras de un verdadero maestro: el tema digital ya le pillaba a él lejos, habituado a su trabajo con fichas, a una metodología analógica, pero entendía que ese sería el presente y el futuro de las nuevas generaciones; y por eso era que él quería apoyarlo, aunque nunca había pensado en utilizar un ordenador, un software específico, o navegar en internet. Con el tiempo, como bien sabes, no solo los utilizó, sino que llegó a tener correo electrónico, lo que por aquellos tiempos resultaba una verdadera excentricidad. Unos años después, retomé los materiales que había preparado para mi memoria de oposición a profesor titular en la Universidad Complutense de Madrid (2000) y publiqué en la editorial Castalia Literatura románica en Internet. I. Los textos (2002). A pesar de mi insistencia en que se publicara en formato disquete o CD-Rom (la gran novedad), la editorial se empeñó en hacerlo en papel, y en muchas librerías del momento -algunas tan importantes como Antonio Machado-, se negaron a no tenerlo en formato libro en sus estanterías, pues para ellos internet y el universo digital estaban llamando a destruir al libro. Tensiones de otros tiempos que ahora nos parecen lejanas, pero que hemos vivido muchos en nuestras propias carnes.

G.R.R: ¿Cree que en ese momento en el que empezó a interesarse por la Informática Humanistica sus colegas lo comprendieron o sufrió el sindrome de la oveja negra?

J.M.L.M: Me temo que sigo, como otros tantos, sufriendo el sindrome de la oveja negra, o más bien, del perro azul; es decir, tanto ayer como hoy muchos colegas no nos ven como ovejas negras, como traidores a la causa filológica, sino como excéntricos, como perros azules que se dedican a algo que, a pesar del aparente interés que suscita, nada tiene que ver con la disciplina y los métodos filológicos. Para muchos colegas, que son visitantes digitales, que usan esporádicamente las redes sociales, que se comunican por correo electrónico y, cada vez realizan más operaciones de su vida profesional y personal en entornos digitales, el universo digital es paralelo al filológico. ¡Qué equivocados están! No han entendido nada, y siguen creyendo que alfabetizar 
digitalmente a los alumnos es enseñarle a utilizar una determinada base de datos o un programa determinado. Hoy hablamos de Humanidades Digitales, de Filología Digital porque queremos mostrar, remarcar que se están creando nuevas herramientas y nuevos modos de difusión que permitirán mejorar nuestros métodos científicos, ampliarlos y llevarlos a lugares impensables en el entorno analógico en el que se fraguaron. Pero dentro de unos años, con estas mismas herramientas -y otras tantas que nos sorprenderán en poco tiempo-, hablaremos tan solo de Humanidades y de Filología, sin más adjetivos, porque lo digital formará parte indisoluble del modo de generar y difundir el conocimiento, haciendo cada vez más accesible la información.

G.R.R:Usted también ha dictado una gran cantidad de cursos de doctorado donde desde épocas tempranas ha incluido temas como las bibliotecas virtuales, el hipertexto, los blogs. ¿Recibió apoyo institucional para llevar a cabo proyectos, comprar software?

J.M.L.M: Ni en el pasado, ni el presente y, me temo, que será difícil esperar esa ayuda institucional en el futuro. Hay una carencia instrumental y de apoyo institucional que ha de quebrarse por algún lugar. ¿Se le ocurre a algún rector o responsable científico montar una Facultad de Químicas sin un laboratorio? Pues así debería ser también con las Humanidades: nuestros laboratorios antes eran las bibliotecas, y las tenemos bien dotadas. Pero ahora también nuestro laboratorio es el entorno digital, con sus programas, con sus servidores, con sus plataformas de edición, con la necesidad de actualizar los servicios ya contratados, de acceder a las fuentes documentales ya existentes para seguir innovando, para seguir produciendo conocimiento. A las empresas de aparatos digitales -Apple, Microsoft, IBM, etc., sin olvidar las que producen los smartphones, la gran revolución de la transmisión del saber de los últimos cinco años, o a las que ofrecer servicios digitales, como Google, o todas las relacionadas con redes sociales- no les podemos exigir que se preocupen por el conocimiento: su mundo es el de la información y el del flujo de esta, de la que obtienen cuantiosos beneficios. Somos nosotros, los científicos, los que tenemos que ser apoyados por las instituciones universitarias o políticas, los que tenemos la obligación de pasar de la información al conocimiento, el gran reto del siglo XXI.

G.R.R:Sabemos que su producción cientifica y literaria es casi infinita. ¿Qué porcentaje ocupa en ellas la reflexión sobre la tecnología y las Humanidades? ¿Han sido todos estos trabajos los que llegó a publicar o se relacionan también con cursos, presentaciones y conferencias?

J.M.L.M: Creo que decir infinita es una exageración que me halaga. Lo cierto es que desde mis primeros escritos -que tenían que ver con la poesía contemporánea española y los textos de los Siglos de Oro-, han sido muchos los temas que me han interesado. Con el paso del tiempo me doy cuenta de que necesito, en un determinado momento, salirme del tema de atención al que he dedicado mi tiempo para abrir el foco y analizar otros temas, que, inevitablemente, terminan enriqueciendo los temas previos, que finalmente nunca abandono: comencé editando y analizando el Libro del caballero Zifar, un romance artúrico del siglo XIV, lo que me llevó a profundizar en la literatura artúrica románica y, en concreto, en su transmisión hispánica; de ahí pasé a los libros de caballerías castellanos, que me llevaron, irremediablemente, al Quijote, y sobre todo a su recepción iconográfica, y de ahí a Cervantes... pero en todo este tiempo, la crítica textual, por un lado, como metodología de base, y las Humanidades Digitales, por otro, como nuevo modo de analizar, comprender y difundir el pasado, se han convertido en un tema recurrente, en un espacio al que he ido volviendo constantemente. Y de esta confluencia nacen algunos proyectos digitales en la Red (el Banco de imágenes del Quijote, El Quijote interactivo en la BNE o Escritores Complutenses 2.0), y también mi reflexión teórica sobre lo que está sucediendo en nuestra disciplina. Una reflexión teórica desde el ámbito hispánico tanto desde España como desde Latinoamérica-, pues la reflexión anglosajona me parece muy pobre al carecer de la base metodológica de la crítica textual y de las escuelas filológicas del siglo XX; y la italiana y la francesa se acercan principalmente a problemas que le son propios. Se ha hecho, se está haciendo y se hará mucho en Humanidades Digitales en el ámbito hispánico: creo que ha llegado el momento de quitarnos ciertos complejos y de mirar a la comunidad científica cara a cara. No tenemos que recibir lecciones de nadie, y menos cuando se hace desde la arrogancia y el desconocimiento, como sucede en muchos de los foros internacionales a los que he asistido. 
G.R.R:De sus proyectos o articulos relacionados con el cruce entre tecnología y Filología, ¿cuál le parece que hoy día es absolutamente actual, el que no ha perecido a manos de los cambios socio-tecnológicos?

J.M.L.M: Del proyecto del que me siento más orgulloso es del Banco de imágenes del Quijote, que se puso en línea en el año 2005. Y creo que es un buen ejemplo del camino a seguir en ese reto del que hablaba, el de transformar la información en conocimiento. En su versión actual, la 3.5 (http://qbi2005.windows.cervante svirtual.com/), se ponen a disposición 17.603 imágenes procedentes de 550 ediciones del Quijote. Pero siendo la información abrumadora $-y$ con ella ya se justificaría un proyecto de esta naturaleza-, al estar hecha por filólogos, por humanistas que conocen no solo las herramientas digitales sino también el texto y su recepción, se ha podido construir una herramienta eficaz y científica de trabajo que ha impulsado el conocimiento sobre el tema. Desde que se puso en la red, han sido decenas las tesis doctorales, trabajos científicos, experiencias docentes a todos los niveles educativos que se han podido realizar gracias a que los materiales no solo están disponibles sino que se acompañan de diferentes herramientas de recuperación de la información, siendo la más novedosa -y solo posible desde las Humanidades Digitales- la que tiene en cuenta tres criterios sobre los contenidos de las imágenes: el episodio, el título y el tema, permitiendo búsquedas a tres niveles textuales diferentes. Este algo más filológico de este proyecto digital es el que abre la puerta al hecho de que la simple información que se hace accesible pueda convertirse en conocimiento de una manera sencilla, desde los más expertos lectores a los más inocentes, a los primeros que se acercan a las aventuras quijotescas.

G.R.R:¿Cómo definiría a las Humanidades Digitales? ¿Cómo cree que se terminarán insertando en las universidades de habla hispana?

J.M.L.M: Las Humanidades Digitales son una rama de las Humanidades que utiliza las herramientas digitales para profundizar en su metodología, ampliar las fuentes y modos de acceder a la información, y para difundir sus conclusiones y resultados científicos. Como decía antes, hoy en día cualquier rama de las Humanidades utiliza estas herramientas digitales de una manera más o menos concreta y eficiente. Con el tiempo, el número de herramientas y de mecanismos de difusión se irá perfeccionando, siendo necesario su uso. ¿Podría hacerse hoy en día un trabajo científico sin contar con las cientos de bases de datos, con las bibliotecas y archivos digitales, o con los cientos de trabajos accesibles en la red? Se puede, pero ya vendría lastrado desde sus orígenes por la falta de actualización bibliográfica y de materiales disponibles. A la pregunta de cómo se insertarán en las universidades de habla hispana las Humanidades Digitales, no sé si será un proceso lento (como el actual), perdiendo muchas oportunidades frente a las universidades de otros ámbitos, como el inglés, el francés o el chino; o, si al contrario, se irán nuestros responsables dando cuenta de que este proceso será imposible de evitar, y que cuanto antes lo comencemos de manera orgánica, antes colocaremos nuestros estudios, nuestros productos, nuestros proyectos al nivel mundial que se merecen. En un futuro muy cercano las Humanidades serán Humanidades Digitales o no serán nada.

G.R.R: Cree usted que será algún día posible que en las universidades iberoamericanas tengamos algo similar a la Digital Philology anglófona, que lleva años en la Academia, que es una disciplina respetada, y hasta está representada por una reconocida revista cientifica? ¿Qué nos falta para llegar hasta alli?

J.M.L.M: Nos falta voluntad política y voluntad académica. Nos falta darnos cuenta de que estamos con las Humanidades Digitales ante un movimiento mundial, que la brecha entre las universidades de habla hispana y las anglosajonas o alemanas no dejará de hacerse más grande si seguimos perdiendo oportunidades y tiempo. La dejadez y la falta de perspectiva de nuestros dirigentes de política académica nos están condenando a vivir en la periferia en los estudios humanísticos del futuro. Y creo que los estudios hispanoamericanos tenemos mucho que ofrecer, pues partimos de unas Humanidades muy particulares. No se trata de ir en contra de nuestra rica tradición filológica y humanística. Todo lo contrario. Se trata de que gracias a un diálogo fructífero con la tradición y las nuevas posibilidades que ofrece el universo digital podamos colocar las Humanidades hispanoamericanas en el siglo XXI. ¿Cómo podemos convencer a nuestros dirigentes de política académica y cultural, a los responsables de nuestros centros universitarios y de investigación? Precisamente, mostrándoles cómo esas universidades, esos modelos universitarios que están a la cabeza de 
todos los rankings que utilizan en sus análisis de la realidad y del presente, están apostando por la extensión de las posibilidades digitales en todos los ámbitos de la ciencia.

El movimiento es imparable. El tsunami del uso de las tecnologías digitales en las escuelas primarias y secundarias - al menos en España, que es el caso que mejor conozco- va a obligar a las Universidades a tener que adaptarse en un tiempo récord. Y lo haremos rápido y mal. Ahora es el momento de comenzar a planear cómo será la universidad para los estudiantes que están trabajando por competencias y por proyectos.

G.R.R: ¿Por quécree que a los humanistas actuales les es difícil acercarse a las máquinas, cuando, por ejemplo, bumanistas de otras épocas como Leonardo Da Vinci, el mismo Gutenberg o los hermanos Banu Musa tuvieron una relación cercana y de erudición con ellas?

J.M.L.M: No sé si el problema son las máquinas o el no haber sido capaces de reconocer todo lo que nos aporta la nueva tecnología digital para poder seguir avanzando en nuestros métodos y formas de trabajar de humanistas. Si pudiéramos analizar a tantos profesores que siguen alentando discursos apocalípticos con la pretendida muerte de nuestra sociedad occidental si se muere el libro, nos llevaríamos más de una sorpresa: el mundo digital ha entrado en sus vidas y ellos utilizan la tecnología digital y las decenas de cacharros que han invadido el mercado de una manera cotidiana y habitual. ¿Por qué no hacerlo en el ámbito académico y científico? Solo se me ocurre una respuesta: la pereza intelectual.

G.R.R:Usted no solo se distingue como catedrático, escritor, sino que también ha curado magnificas exposiciones sobre literatura y artes. ¿Le queda alguna asignatura pendiente con relación al tema Humanidades Digitales?

J.M.L.M: Me queda una, un sueño: diseñar y crear una plataforma de edición estandarizada para mostrar las nuevas posibilidades para difundir nuestros textos en un nuevo medio, más allá de las imposibilidades y limitaciones del universo analógico. No hablo de cambiar el método de la crítica textual, sino de todo lo contrario: convertir la crítica textual en el centro de los esfuerzos de una Filología Digital, en el motor unificador de muchos de los cambios y de las herramientas que se están experimentando gracias a la tecnología digital. Cada día estoy más convencido de que las Humanidades Digitales son la gran oportunidad para situar de nuevo a la crítica textual en el lugar central de los estudios filológicos, tal y como en el siglo XIX y en la primera mitad del XX. La textualidad digital está todavía por explorarse.

G.R.R: Y finalmente, y ya pensando más allá de las Humanidades Digitales, ¿cómo se ve usted en 10 años enseñando Filología en la universidad?

J.M.L.M: ¿Cómo me veo? Me gustaría imaginarme consiguiendo despertar una duda en mis alumnos, una de esas miradas en que la mente comienza a funcionar porque acaba de descubrir un nuevo camino, una nueva ruta, que hay que explorar. Una de esas miradas que justifican el trabajo de un profesor, que no es otro que conseguir comunicar al alumno todo lo que sabe para que el alumno pueda seguir avanzando, explorando nuevos caminos, ampliando nuestro horizontes y nuestras perspectivas. Y no me cabe ninguna duda de que, unido a los cambios tecnológicos que viviremos en los próximos años, les compete a esos alumnos hacer realidad mis sueños de ahora, sus sueños de dentro de diez años. Y dentro de diez años seré feliz sabiendo que, al menos, tuve la oportunidad de plantar una semilla del cambio y que ese cambio está dando sus frutos. Que esta sensación, que ese proceso de enseñanza lo haga en una clase 2.0 (o 3.0, 4.0, etc.), o que lo haga en mi clase de siempre, con una amenazadora pizarra que nunca utilizo, no me importa tanto como imaginarme enseñando dentro de diez años con la pasión -y con los nervios y la incertidumbre- con la que entro en el aula ahora mismo. 